\title{
The Nachlass Self-contained: The Textual Genesis of Wittgenstein's Philosophical Investigations by Nuno Venturinha
}

\section{Marcos Silva}

Review: Venturinha, Nuno (Ed.). The Textual Genesis of Wittgenstein's Philosophical Investigations. Routledge: New York, 2013. 256 pages.

Venturinha's intriguing book represents a welcome consolidation of Wittgenstein's Nachlass as a source for scholarship, and one that speaks to the growing centrality and international impact of the Wittgenstein Archives at the University of Bergen in Wittgensteinian studies. This book comes as a natural development of Venturinha's previous work Wittgenstein After His Nachlass (Palgrave 2010), and follows a similar structure: Venturinha brings leading Wittgenstein scholars together to discuss and evaluate the import of Wittgenstein's Nacblass in the interpretation of his philosophical development. The collection of essays presents new discoveries within the most recent research on the Nachlass, including new material competently translated into English by James Thompson and discussed by Venturinha. In 2010, they presented a translation of Ramsey's text dictated by Wittgenstein and now they present a text by Wittgenstein himself that never received a von Wright number.

Venturinha's new collection focuses on the philosophical and philological studies of Wittgenstein's intellectual development to his socalled mature philosophy, or as Venturinha states it, the genesis of the Philosophical Investigations (PI). The great diversity of topics covered in this volume (e.g., literature, religion, arts, mathematics, logic, etc.) speaks to the many philosophical setbacks and breakthroughs which Wittgenstein experienced following the publication of the Tractatus. Venturinha displays an open-mindedness to different perspectives on the philosopher by publishing opposing interpretations 
of his works (with the inclusion of Lugg's and Schroeder's papers, for instance), and he takes on the editorial challenges of the Nachlass to promote an integrated view of the genesis of the PI. This work sheds light on many difficult remarks in Wittgenstein's mature work by tracing key discussions and presenting insights as to the rise and development of his most potent ideas. In this collection, no text falls into the easy temptation of finding a lost key to Wittgenstein's canonical texts in the Nachlass.

After reading Venturinha's new book, it is hard not to become convinced that the PI is indeed what one might call an "impossible book". For Wittgenstein, the creation of the text did not merely involve a long and complex process of polishing and rearranging ideas, but was also an epic struggle against his own limitations through a philosophical labyrinth of original concepts. The work demanded of him a herculean and sophisticated combination of philosophy and writing.

Aside from very competent works by Schulte, Hacker, Klagge, Schroeder, and Lugg, Venturinha's introduction represents one of the most interesting contributions in the book, as it adeptly puts into perspective the difficulties involved in editing Wittgenstein's material and other posthumous work by Kant, Heidegger, Nietzsche, and Pascal. Comparing Wittgenstein's work to the work of an artist, Venturinha convincingly shows
Wittgenstein's work as a composite art.

Venturinha's book is divided into two main parts: the first part focuses on what he calls argumentative uses and the second part focuses on the significance of logic and mathematics. The organization of the chapters within these parts is well-structured, with five contributions given in each part, as well as fluid, with the essays of one part progressing cohesively into the next. The first part of the book begins with a contribution by Citron that explores some of Wittgenstein's mysterious remarks on theology as grammar. Drawing on unpublished notes by Moore from 1930-33, Citron defends religious discourse as a paradigm for Wittgenstein of the indeterminateness of language. In the second paper in the book, Smith defends the view that the Blue Book is a preliminary study for the PI, discussing the rise of certain concepts that are crucial for Wittgenstein's mature thinking, such as family resemblance and language games. Klagge's paper then investigates who it was that Wittgenstein addressed in the 1930s in terms of an insightful distinction between esoteric goals (addressing a private group of pre-initiated individuals) and exoteric or evangelist goals (aiming at changing the mentality of people engaged in a different mode of thinking). Following Klagge, Pichler examines the sense in which Wittgenstein might be considered a syncretistic author through a discus- 
sion of his famous album metaphor. Pichler's contribution analyzes the PI as an open enterprise, tackling Wittgenstein's careful arrangement of remarks. Lastly, ending the first part of Venturinha's collection, Schulte's skilled paper offers a contribution on the degree of sophistication in the Umarbeitung of the Big Typescript, which according to Schulte is more a collection of remarks for future writings than a final book. Schulte defends the claim that even where the PI and Big Typescript overlap, the latter does not necessarily anticipate the former in any relevant way.

The first part of Venturinha's book is perhaps best suited for scholars of Wittgenstein, especially for those interested as much in the Nacblass as in the philosopher's final works. It appears questionable whether people engaged in current philosophical issues would care much about Wittgenstein's every change of mind and rewriting of various passages; some could consider this sophistication in investigating Wittgenstein's Nachlass to be a philological distraction rather than a real gain in philosophy. The relevance of Wittgenstein's thinking today is somewhat neglected in the second part of Venturinha's book, which focuses on logic and mathematics. Neither Venturinha nor his book's contributors give an explicit reason as to why the second part concentrates solely on these subjects over, say, Wittgenstein's thinking on the philosophy of mind, episteme- ology, religion, anthropology, or language. It is also disappointing that some leading issues in logic and mathematics go unmentioned, and that logic and mathematics are not treated with greater distinction from one another. Furthermore, nothing strikingly original is defended in the second part of Venturinha's book.

In the first contribution to this second part, Kuusela discusses Wittgenstein's arguments against empiricism and conventionalism, defending his apriorism as a cultural one. Kuusela's paper gives a very good introduction to Hacker's insightful paper on transcendentalism in Wittgenstein's philosophy. Following this, Hacker's (negative) answer to the question of a Kantian influence in the Tractatus and the PI is very fruitful in terms of elucidateing the extent to which Wittgenstein made use of transcendental arguments in his work. Hacker shows how, in Wittgenstein, the a priori is connected to culture and grammar as interwoven networks of rules. In the book's eighth paper, Lugg argues that there is no conclusive argument for a significant transition from the calculus model of language to the language-game model in Wittgenstein's philosophy. In the subsequent paper, however, Schroeder defends the claim that this transition indeed exists in Wittgenstein's work and that it is the result of his acknowledgement of mathematics as a fully rulegoverned activity and (natural) language as opposed to an exact activity. In opposition to Lugg's 
thesis, Schroeder advocates that for Wittgenstein, while a calculus is fixed, a game is open and indeterminate. Schroeder also explores an interesting distinction between a rule as a semantical norm and a rule as an instruction for actions, defending the idea that the philosopher arguably never made this distinction properly. Maury's contribution ends Venturinha's book by examining Wittgenstein's famous discussion of rule-following in mathematics. The piece does not really approach the extensive literature on this topic. Maury discusses the issue of the status of proofs using another famous distinction, the distinction between saying and showing, whose vast literature Maury also leaves out. $\mathrm{He}$ argues that a rule of inference is shown in reasoning, and this means that an inference is not a third thing being stated or said between, say, two propositions. This is the mistake, he argues, that Russell made in his Principia.

What is surprising about Venturinha's new collection of papers is that it includes very little engagement with current accounts of logic and mathematics, particularly given that some concepts in these areas today have a Wittgensteinian flavor, such as inferentialism and the proof-theoretical and dialogical approach to logic. This lack of engagement gives the impression that Wittgenstein's thinking is isolated within the discussions of Wittgenstein scholars alone. Moreover, in the second part of
Venturinha's book, there is little critical assessment of Wittgenstein's very controversial remarks on mathematics and logic.

The papers published in Venturinha's book make several argumentative and conceptual connections within Wittgenstein's philosophical development documented in his Nachlass, yet virtually no connections to other authors during this period are mentioned. For example, when discussing logic and mathematics, it is surprising that Ramsey is not mentioned at all, as he was one of the authors who triggered Wittgenstein's criticism of his early philosophy in the beginning of the 1930s. Actually, in Venturinha's book, the use of Philosophische Bemerkungen, Some Remarks of Logical Form and Wittgenstein und der Wiener Kreis, texts from Wittgenstein's (early) middle period, is very poor. Is the implication here that these texts did not play any relevant role in the genesis of the PI? If so, this claim seems misguided, as Wittgenstein appears to be defending, for instance, certain constructive and paraconsistent kinds of reasoning already in these texts.

In Grundgesezte II (1903), Frege incidentally uses the notion of a conflict of rules (Widerstreit der Regeln) to explain what contradictions there are in critically evaluating certain formalist accounts of mathematical practices and entities. In 1930, when Wittgenstein was preparing Waismann to represent him in a very influential 
panel on the philosophy of mathematics to be held in Königsberg, he explicitly borrows the notion of a conflict of rules from Frege to criticize Hilbert's metamathematical enterprise, especially his account of inconsistency (Widerspruchsfreibeit). Due to his discussions with members of the Vienna Circle (19291932), some authors suggest that Wittgenstein may be understood as a forerunner of paraconsistent logics, a subject of great interest in both contemporary philosophy and logic. In fact, during these discussions and in other texts of the same period, the author of the Tractatus surprisingly reacts very tolerantly to aspects of non-classical logics, especially in terms of formal contradictions.

As these "tolerant" discussions, concepts, and arguments on nonclassical logics reappear several times in Wittgenstein's mature texts, such as in Remarks on Foundations of Mathematics, Lectures on Foundations of Mathematics, and in the PI itself, it would have been important to include a contribution in this book concerning Wittgenstein's potential status as a forerunner of nonexplosive logic, as this could shed some light on his philosophy of logic and mathematics, as well as relate to the genesis of the PI itself. Such an investigation could show why Wittgenstein's notion of rules in a game could represent a seminal philosophical alternative to understanding the nature of contradictions without appealing to dialetheias. In the beginning of the 1930s, Wittgenstein's focus was neither on formal trivialization nor on any mandatory collapse of calculi that entail contradictions in logic, but rather, he was already developing a very comprehensive anthropological account of logic. A proper account of this development might help to articulate, through the notion of normativity and rules, the nature of formal systems and the relevance of human practices in the construction of both paracomplete and paraconsistent logics. Unfortunately, the topic of normativity, which is central in many contemporary discussions on epistemology, ethics, and logic, is discussed only marginally in Schroeder's and Hacker's contributions. This is a pity, as normativity appears to be an area in which Wittgenstein's philosophy might be most relevant to contemporary philosophy.

Venturinha's book may shed light on central questions in Wittgenstein's philosophical development during the 1930s, but it systematically overlooks the philosopher's controversial engagements with his contemporaries of the time. For instance, authors that Wittgenstein was explicitly discussing with members of Vienna Circle in 1930 were Frege, Husserl, Brouwer, Ramsey, Hilbert, Weyl, Sheffer, Bernays, Russell, Carnap, Hahn, Poincaré, Tarski. Therefore, if Wittgenstein was clearly not isolated, why do leading Wittgenstein scholars treat his philosophical development as existing in isolation? 